\title{
SURVEYING BIM IN THE LEBANESE CONSTRUCTION INDUSTRY
}

\author{
*Rita Awwad \\ Assistant Professor \\ Department of Civil Engineering \\ Lebanese American University \\ Byblos, Lebanon \\ (*Corresponding author: rita.awwad@lau.edu.lb) \\ Michael Ammoury \\ Graduate Student \\ Department of Civil Engineering \\ Lebanese American University \\ Byblos, Lebanon
}




\title{
SURVEYING BIM IN THE LEBANESE CONSTRUCTION INDUSTRY
}

\begin{abstract}
Building Information Modeling (BIM) has been gaining a significant edge in the construction industry over the last decade. BIM allows gathering all building information in one shared database that can help all construction entities better understand, integrate and visualize all work progress from inception to operation of the building. The main purpose behind BIM is to bring all project participants together (Client, Architect, Contractor, Consultant) since the initial stages of a project allowing them to cooperate and work as a team in the promise of an increased productivity, reduced cost, enhanced quality and faster delivery. However, a full-fledged implementation of BIM tools and benefits is not yet achieved in the construction industry and remains a debatable issue for researchers and practitioners in the construction field. This paper aims at assessing BIM awareness and usage in the Lebanese construction industry through conducting interviews with contractors, architects and consultants that are key players in the Lebanese market. A comprehensive literature review about BIM adoption in some developed countries and in the surrounding region is also provided in order to better evaluate the Lebanese industry status in comparison with foreign industries. This research sheds the light on BIM awareness of the different construction parties in the Lebanese market, assesses the extent of its current use, identifies the pertaining implementation challenges, and provides recommendations to enhance BIM role in the Lebanese construction industry.
\end{abstract}

\section{KEYWORDS}

Building documentation, BIM Awareness, Building information models, BIM challenges, Lebanese construction market.

\section{INTRODUCTION}

Building information modeling (BIM) is a relatively new process that has been the subject of many publications in the construction literature. BIM may be defined as the process of constructing a 3D digital representation of a building that aims at sharing project information and facilitating the communication between the different parties involved in a project from inception to completion, extending further to maintenance of the building. A BIM model of a building is a central database that integrates all different pertaining engineering plans such that updating a single feature on one drawing is reflected upon the entire model.

BIM is not just another CAD (computer aided design) model but rather it can simulate a 5-D construction process, where time and cost are the two additional dimensions. It has numerous benefits among which clash detection, elimination of design errors, and reduction in disputes and conflicts. Although many practitioners realize the benefits of BIM such as reduction in change orders (COs) and requests for information (RFIs), reduction of project delays, and accelerated discovery of construction conflicts (Gael and Issa, 2011), BIM implementation is still in its primitive stages especially in the developing countries.

This paper presents a qualitative survey that aims at assessing BIM status, awareness and adoption in the Lebanese construction market, through conducting interviews with a group of industry professionals from diverse backgrounds. This survey serves to identify most commonly used BIM features, the firms' 
level of expertise in implementing BIM, challenges faced, and potential for improvement, and concludes by providing recommendations to enhance the use of BIM in the local market.

\section{ROLE OF THE PUBLIC SECTOR IN ADVANCING BIM WORLDWIDE}

Over the past few years BIM has been gaining more popularity in the construction sector among stakeholders. One of the key motivators behind BIM adoption is the public sector, which plays a major role in accelerating the shift towards BIM.

In the USA, the General Services Administration was the first government organization to lead the US government into BIM and had a primary role in promoting BIM in the entire industry (National Institute of Building Sciences, 2011), where it required BIM for spatial validation on all projects. Moreover the U.S. Army Corps of Engineers published in 2006 guidelines for implementing BIM which were updated in November 2012 (US Army Corps of Engineers, 2012). In addition, the states of Wisconsin and Texas mandate the use of BIM for most new projects. Moreover, the State of Ohio issued a BIM Protocol that provides general guidance to ensure that "building owners know what they should include in their requests for qualifications, agreements, bidding requirements, contracts, and other documents affected by this new medium." (State of Ohio BIM Protocol, 2010).

As for the European continent, the UK government has taken a big leap towards the adoption of BIM, where by 2016 the use of 3D collaborative BIM will be mandatory on all public projects in excess of 5 million pounds. BIM is gaining grounds in Netherlands too. The Government Buildings Agency that manages and develops the state's largest property portfolio in Netherlands, has mandated BIM and has issued the RGB BIM norm that describes general requirements and specifications for BIM extracts ((BuildingSMART, 2012).

Moreover, Scandinavian countries are pioneers in BIM implementation. As of 2007, the Finnish government owned Senate Properties firm requires building models to meet IFC standards. Also, the Finnish government provides subsidies for research and development programs related to BIM. In Norway, the country's public construction and property management representative "Statsbygg company" requires the use of BIM on open international standards in all public projects (Granholm, 2011).

In Asia, Singapore government has been the leader in the BIM adoption process and one of the few Asian countries who have implemented BIM in the public sector (Wong et al., 2009). In order to enhance productivity in the construction sector in Singapore, the Building Control Authority (BCA) has come up with a five-year plan to move the industry towards the adoption of BIM. BCA will mandate "electronic submissions in BIM format for architectural, structural, mechanical and electrical plans for building works for regulatory approval by 2015, starting with architectural e-submissions in 2013." (BCA, 2013). Moreover BCA has developed a fund especially dedicated for companies who are willing to adopt BIM. The fund pays part of the cost incurred in training, consultancy, software or hardware, up to $50 \%$ of the costs capped at $35000 \$$ per firm for the project collaboration scheme. These measures are applied to encourage companies to shift to BIM. Furthermore, the Australian federal government proposed July 1 2015 for mandating BIM on all public projects and has commissioned buidingSMART to prepare a strategy for BIM implementation. (Autodesk University, 2012)

On the other hand, the Middle East region has the lowest BIM adoption rate compared to the aforementioned developed countries. In fact, the public sector in the Middle Eastern countries is not taking any steps towards mandating the use of BIM at least for public projects. A survey about Middle East based firms mainly operating in the gulf area showed a BIM adoption rate equal to 25\% (McGraw-Hill, 2011). These companies use BIM mainly for basic tasks such as 3D visualization, drawing extraction and rarely planning. The survey respondents identified main obstacles against using BIM such as availability of skilled staff, followed by the cost of software and implementation, and the availability of training, etc. 
As part of the Middle East region, Lebanon's public sector has not taken any steps to push the industry in the direction of BIM. Such efforts remain an individual initiative by construction professionals depending on their BIM awareness and their willingness to adapt.

\section{SURVEY FINDINGS}

\section{Profiles of Interviewees}

This paper aims at assessing BIM awareness and adoption in the Lebanese construction industry through conducting a qualitative survey that consisted of interviewing sixteen industry professionals. Fifteen interviews were conducted with key consulting firms, construction companies and developers in the construction market, and one additional interview with a BIM training firm. The survey participants occupied various positions in their companies namely owners, project managers, and senior engineers/architects. Thirteen of these firms are based in Lebanon of which $47 \%$ work also on international projects in the Middle East region, while the remaining two are based in UAE and Qatar and operate mainly on projects in the surrounding region.

Figure 1 shows the distribution of interviewed companies by number of employees and Figure 2 shows their classification. As observed, around $60 \%$ of the companies are large companies with more than 100 employees. As for their classification, consultants formed half of the interviewed sample, followed by contractors and then developers.

The survey questions were divided into three categories: (1) Obtaining background about the interviewed companies such as firm size, client nature (public/ private), operational region and scope, number of employees, and service years in the market; (2) In case of a BIM user, the participant is asked about types and percentage of projects using BIM, reasons for adopting BIM and features used, advantages and implementation challenges, and suggestions for improvement; (3) In case of a non-user of BIM, the participant is asked about the techniques used to store data about its projects, ways adopted to keep track of information flow on site and to ensure good communication among project entities, awareness about BIM benefits and what hinders the switch, willingness to adopt BIM, incentives, concerns and expected return on investment from using BIM.

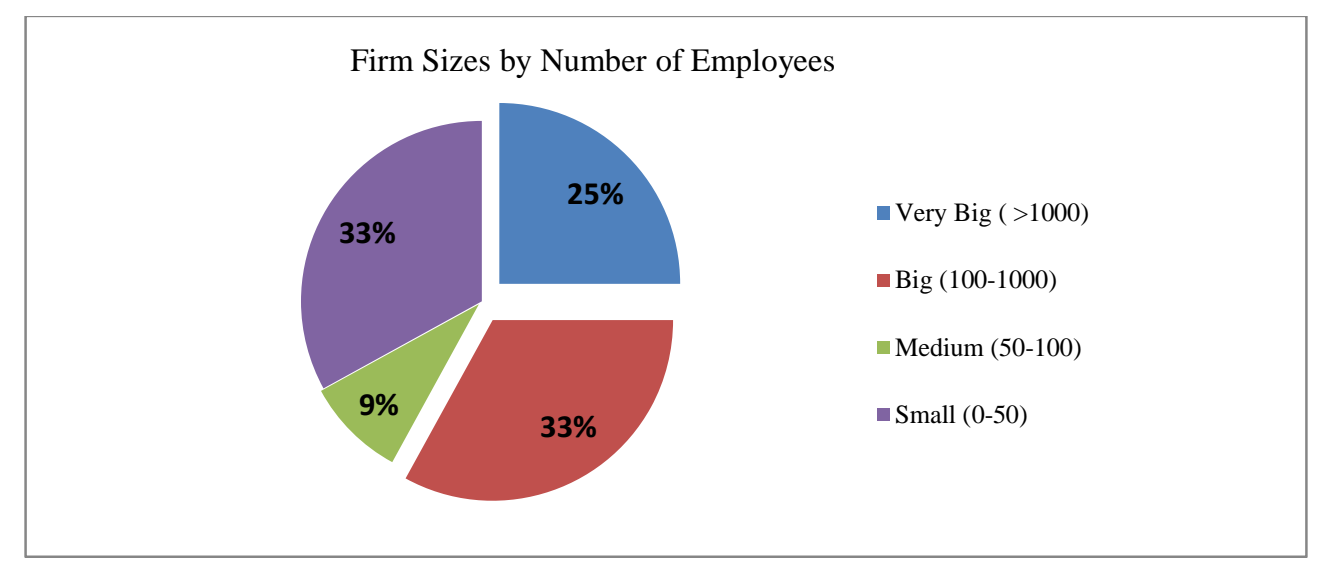

Figure 1 - Firm Sizes by Number of Employees 


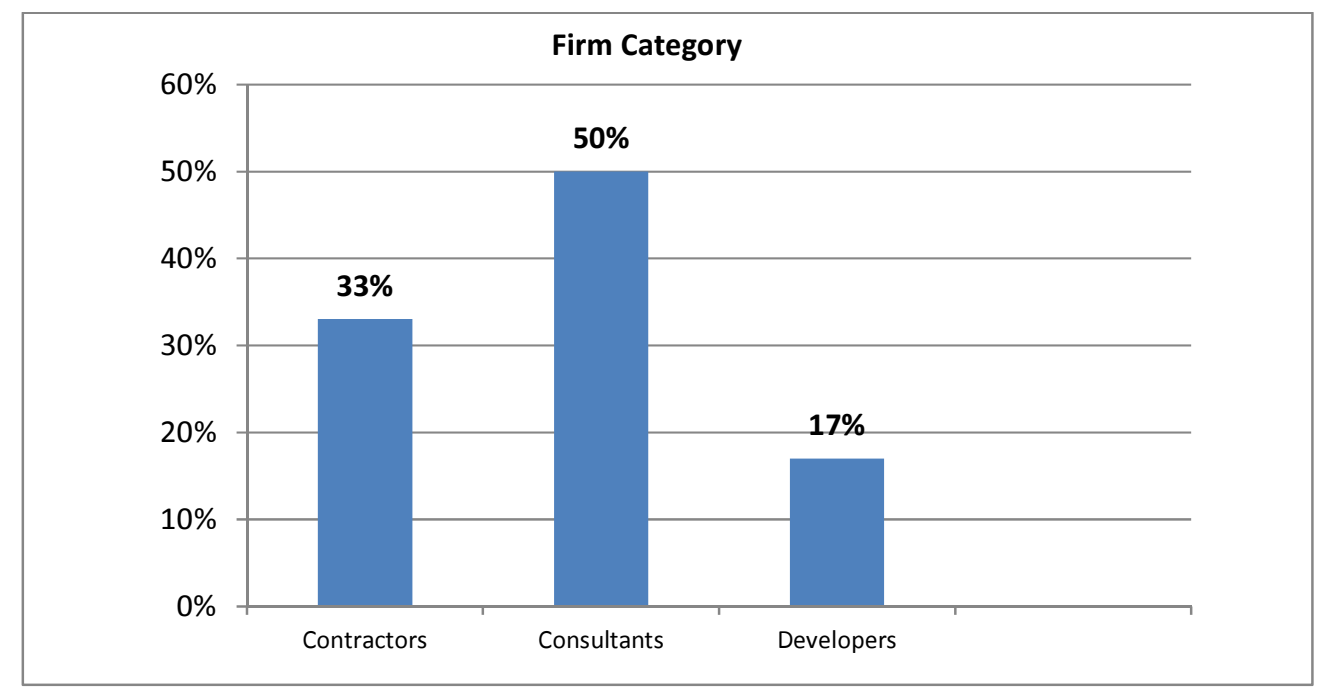

Figure 2 - Firm Category Distribution

Survey Analysis

$\underline{\text { BIM Users }}$

Among all the surveyed firms, only large companies are using BIM in Lebanon. Six out of the fifteen interviewed companies have adopted BIM and are using it on their building projects. Additionally, one of these firms, a large contracting company, has recently started using BIM on road projects. Note that $75 \%$ of the surveyed BIM users are working on international projects in the Middle East region. Despite the aforementioned, BIM usage in the Lebanese market is still in its early stage where most of the firms use $\mathrm{BIM}$ only for $3 \mathrm{D}$ visualization, clash detection, quantity surveying and $2 \mathrm{D}$ drawing extractions, with very few using it for scheduling and planning, and none applying it in the management phase of a project. Furthermore, BIM adoption is still partial in the sense that $80 \%$ of the participants using BIM apply it on less than $60 \%$ of their projects. Most of these companies have been using BIM since a maximum of 3 to 4 years and are trying to follow a gradual shift to BIM through training their personnel on the software and applying it on a project by project basis. The survey participants listed various reasons behind the gradual transition to BIM. Some of them referred to the client being the main initiator, and others used BIM in the hope for a better collaboration and higher profit, and a desire to become the BIM leaders in the market. Another interesting answer provided by one of the consulting firms is that its ultimate goal is to integrate sustainability models in the whole BIM process. The common stated reason behind adopting BIM is the participants' strong belief in BIM advantages and benefits and its potential to enhance construction quality and reduce costs.

The survey showed that $83 \%$ of the respondents using BIM utilize Autodesk BIM software in general and Revit in specific. To elaborate further on this issue, one of the interviews was conducted with a key Autodesk BIM training firm that has been in the market for almost 5 years. The respondent classified his clients as students interested in learning the software, employees sent by their supervisors to enhance their knowledge about the product, and independent designers that work as free-lancers in the market. The respondent indicated that although Autodesk products are very common in Lebanon and the surrounding region, BIM software use is still at a primitive level, advancing slowly year after year. The participant also indicated that BIM training firms do not teach how to integrate different models of the project and how to collaborate between different software applications but rather focus mainly on some BIM aspects such as $3 \mathrm{D}$ visualization and the extraction of $2 \mathrm{D}$ drawings. 
BIM users were also asked about the main challenges faced while initiating the shift towards BIM. Resistance to change was the main concern where people find it hard to learn a new technology and to perceive its advantages a priori. For example, one consulting firm stated that out of 70 engineers trained to use Revit software, only 6 are using it effectively. Other main concerns expressed by the respondents are the time required to implement the change, its impact on the company operations and short-term profit, and the costs associated with training and implementation.

Another objective of the survey was to determine the different views of respondents about the major benefits realized through adopting BIM and the relevant setbacks. Four out of six BIM-users witnessed a main improvement in the project design development phase through using clash detection features of BIM software and due to enhanced collaboration between the different project entities, which resulted in reducing design errors to a large extent. Moreover, about $67 \%$ of the respondents reported a significant reduction in claims and disputes. Additionally, answering whether BIM adoption resulted in project time reduction and cost savings, most participants stated that they have seen a slight but promising decrease in time and cost as they applied BIM on more and more projects. For instance, one large consulting firm observed a much faster production of shop drawings as a result of using BIM. To summarize, most of the respondents were in agreement that BIM adoption and implementation is a learning process and thus savings are expected to be realized better over time. They also emphasized the importance of having all project parties (architect/designer, contractor, and subcontractors) apply BIM in order to benefit more from a full-fledged implementation.

As mentioned previously, the Lebanese construction industry is still at the preliminary stages of a complete implementation of the BIM approach. Thus, a main objective of the survey was to determine which BIM aspects or features are mostly used by the survey participants who have introduced BIM into their operations. Figure 3 shows that 3D visualization is the most common feature used by all participants, followed by quantity surveying used by almost two third of the surveyed BIM users, followed by building design and clash detection features used by half of the participants, and finally shop drawings, as-built drawings, design review and cost control functions used by around $17 \%$ of BIM users. As observed, the interviewed companies are being selective through using certain aspects of BIM depending on their needs and hence, are not fully benefiting from a complete BIM implementation that stretches from inception to operation of the building. In order to achieve the latter, respondents reported some technical issues that need to be resolved such as interoperability and the lack of a common unified standard, model integration issues, the software's ability to handle and process mega projects, and the lack of expertise of available software training firms.

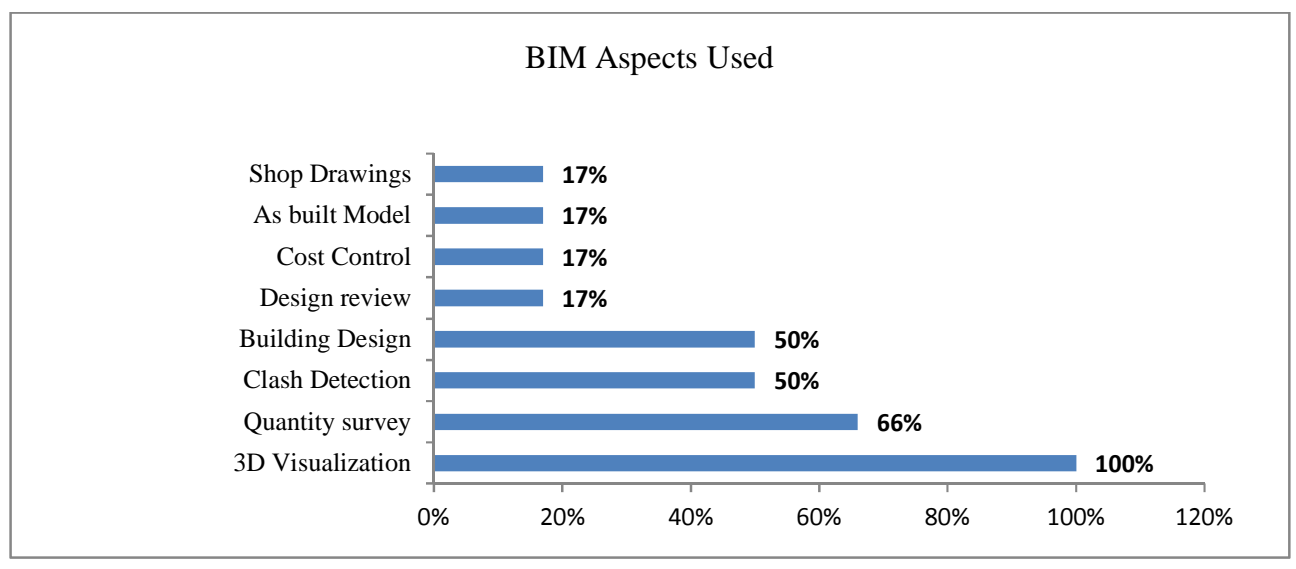

Figure 3- Major BIM aspects used 


\section{$\underline{\text { BIM Non-Users }}$}

A separate questionnaire was prepared for BIM non-users. Unlike the firms implementing BIM, $77 \%$ of the firms not using BIM ranged from small to medium size firms. It is worth noting that 3 out of these 10 firms have never heard about BIM. $78 \%$ of the participants expressed willingness to adopt such a technology and identified possible motivating factors that might incite them to start using BIM such as better productivity and efficiency, time saving, easiness in use and flexibility, improved quality and cost control, reduction in design errors and disputes, clash detection, and most importantly if the client requests so. Figure 4 shows these different motivators and their corresponding percentages representing how many of BIM non- users showed interest in each.

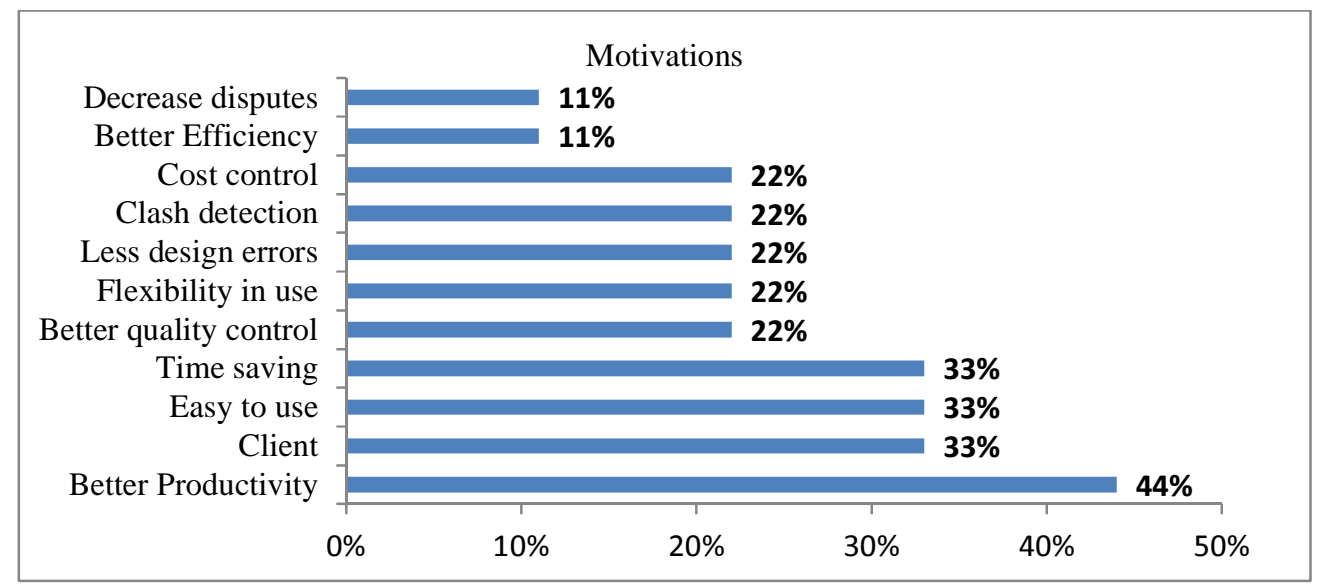

Figure 4 - BIM non-users motivations for adopting BIM

Besides motivating factors, interviewees showed concerns inhibiting BIM adoption such as lack of skilled labor, lack of BIM popularity and awareness in the market, required time for shifting, cost of training, and others as shown in Figure 5.

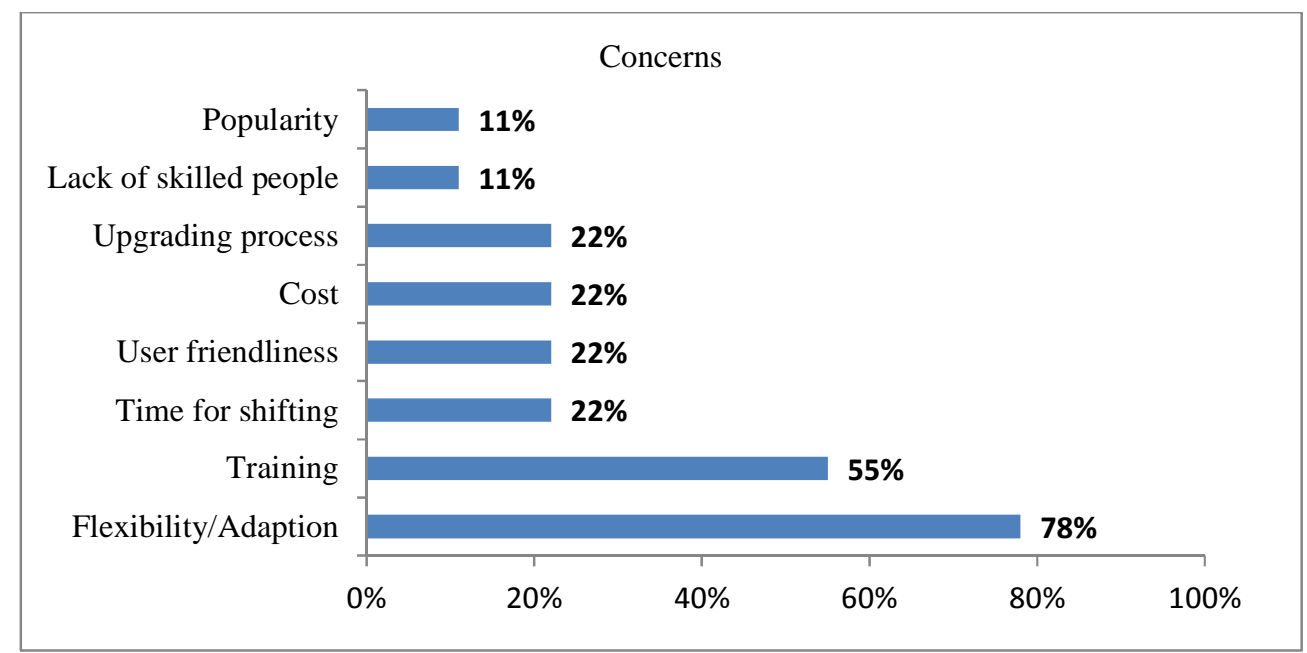

Figure 5 - BIM non-users concerns for adopting a new technology 
In addition to the concerns mentioned above, the survey identified other factors that hinder construction firms in the Lebanese market from using BIM. For instance, three out of five contractors stated that the lack of BIM popularity among subcontractors makes it much more difficult for them to fully benefit from BIM adoption. Another contractor explained that most of the contracts he deals with are design-bid-build contracts which does not require collaboration between different parties at the early stages of the project and thus does not allow for benefiting from a BIM full implementation. Furthermore, resistance to change was a major setback according to $30 \%$ of the respondents.

This survey demonstrated that lack of BIM awareness in the Lebanese market is a major cause behind its limited implementation. Thus, it is very necessary to hold conferences, workshops and discussion forums to enlighten the different construction industry professionals about the meaning of BIM, the corresponding approach and its numerous benefits, and to remove the surrounding ambiguity. Along the same lines, this paper conducted a brief overview over top universities in Lebanon and the surrounding region to check how popular BIM is in their curriculum.

\section{$\underline{\text { BIM in Academia }}$}

The curriculums of 18 top engineering schools in the Middle East region were revised and investigated thoroughly to find out that only $28 \%$ include BIM as a course at the graduate level or as a part of a scheduling course at the undergraduate level. None of these colleges have BIM as a requirement for engineering students. Figure 6 shows the distribution of colleges by country. On the Lebanese front, only two out of seven surveyed universities offer BIM as an elective course to their students. These findings show further the lack of BIM awareness in the market.

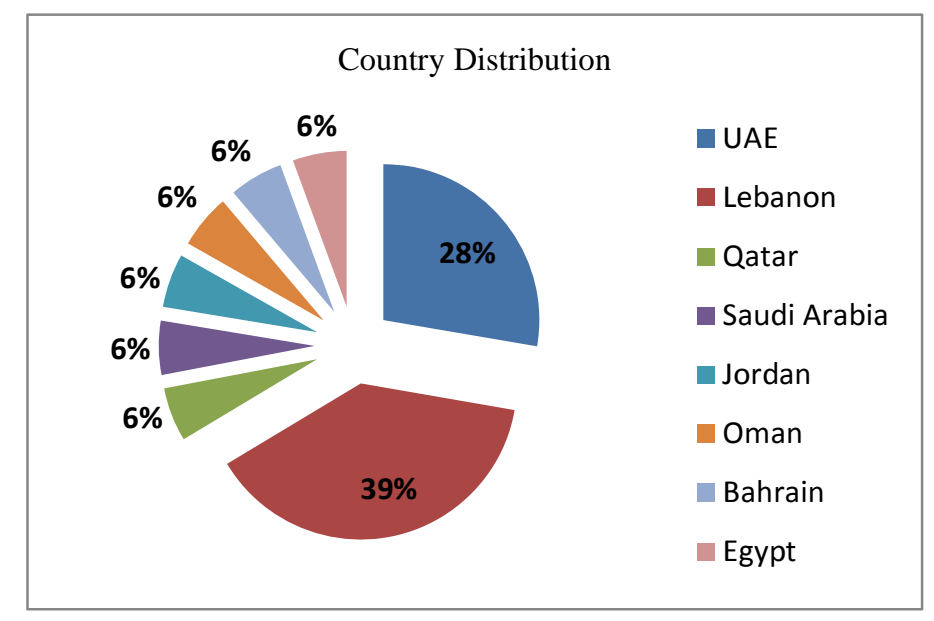

Figure 6 - Academic Institutions surveyed by location

\section{CONCLUSIONS}

Based on the presented survey findings, it can be concluded that BIM adoption is still slow and primitive in the Lebanese market. Large companies are mainly the ones initiating the shift towards the BIM culture whereas medium to small companies are still reluctant to change and sometimes ignorant about BIM.

The main obstacles hindering the fast development of BIM in the market are : (1) The absence of collaboration between different entities (consultant, designer, client, contractor, and subcontractors) since the beginning of the project due to the common design-bid-build tendering approach (2) the lack of 
awareness about BIM, its different features and the corresponding benefits, (3) the absence of BIM courses from most engineering curriculums at universities, (4) the absence of the government from providing any incentives or from mandating BIM implementation at least on public construction projects, and (5) the lack of follow-up on BIM implementation and its results after obtaining BIM training.

Thus, in order to ensure a full-fledged BIM implementation and to benefit completely from its advantages, all entities on a project should make sure to use one BIM integrated model where they can share all data and make decisions collectively, as most respondents answered. Also, BIM awareness should be increased among the public in general and engineers in specific through organizing workshops and lectures about the topic, its challenges and benefits, and by introducing it further into the different university programs.

Despite all the aforementioned challenges, $80 \%$ of the surveyed BIM users have agreed that BIM is mature enough to initiate a global shift in the construction market.

\section{REFERENCES}

Autodesk University (2012). BIM Implementation in Australia. Retrieved from:

http://au.autodesk.com/?nd=class\&session_id=10444

Building \& Construction Authority (BCA) (2013),4-Day Certification Course in BIM Modelling, Retrieved from BCA website: http://www.bca.gov.sg/academy/courses_tests.aspx?Course_Exam_Code=CS001515

BuildingSMART (2012). Statements and Guidelines. Retrieved from:

http://iug.buildingsmart.org/resources/statements-and-guidelines.

Gael, B. and Issa, R. (2011). Return on investment analysis of using building information modelling in construction. Journal of Computing in Civil Engineering. , 1.doi:10.1061/(ASCE)CP.1943-5487.0000164.

Granholm L. (2011, March). Ongoing change on different markets. Presented at International conference. Abu Dhabi, UAE.

McGraw-Hill (2011). BIM in the Middles East 2011: The reality and the way forward (Survey Report). Retrieved from: http://www.bimjournal.com/wp-content/uploads/2011/05/Full-BIM-Report-Web.pdf

National Institute of Building Sciences (2011). BIM initiatives: Government. Retrieved from:

http://www.wbdg.org/bim/initiatives_bim.php

Ohio Department of Administrative Services (2010). State of Ohio Building information modeling BIM Protocol (Tech. Rep. No. M940-01v0710-draft).

The US Army Engineer Research and Development Center (2012). US army corps of engineers roadmap for life-cycle building information modeling (BIM) (Tech. Rep. No. ERDC SR-12-2 ). Washington, DC: US Army Corps of Engineers Directorate of Civil Works Engineering and Construction Branch.

Wong, A.K.D, Wong, F.K.W. \& Nadeem, A. (2009) Comparative Roles of Major Stakeholders for the Implementation of BIM in Various Countries, Integration And Collaboration 3, Changing Roles. 